\title{
Barriers to Exclusive Breastfeeding among Urban Mothers
}

\author{
Lazina Sharmin $^{1}$, M. A. K. Azad Chowdhury ${ }^{2}$, Soofia Khatun ${ }^{3}$, Naser Ahmed ${ }^{4}$ \\ Received: April 12, 2015 Accepted: April 25, 2016 \\ doi: http://dx.doi.org/10.3329/jemc.v6i2.27763
}

\begin{abstract}
Background: Breastfeeding is the unique source of nutrition and it plays an important role in the growth, development and survival of the infants. The initiation of breastfeeding within one hour and continuation of only breast milk up to six months ensure maximum benefits. The prevalence of exclusive breastfeeding in Bangladesh is 56\% which is low. We designed this study to find out the factors influencing the duration of breastfeeding in Bangladeshi population. Objective: To study the factors influencing noncompliance to exclusive breastfeeding. Materials and Methods: This cross sectional study was conducted in Dhaka Shishu Hospital during the period January to June 2011. It includes 125 infant (1-12 months)-mother pairs randomly selected from the inpatient and outpatient departments of Dhaka Shishu Hospital. Mother-infant pairs were divided into two groups based on continuation of only breastfeeding up to six months. Outcomes were compared between two groups. Results: In this study exclusive breastfeeding was found in $27.2 \%$ and nonexclusive breastfeeding was in $72.8 \%$ cases. It was found that in most cases $(40 \%)$ termination of breastfeeding was at 3-4 months. The study revealed that insufficient milk production due to poor position and attachment, social factors such as influence of husband and other family members, joining to service etc act as barrier to exclusive breastfeeding. Mass media and advice from health professionals had a higher influence on lower rate of exclusive breastfeeding. Women who were multiparous, housewives were more likely to maintain optimal breastfeeding. Conclusion: The present study reveals some important factors contributing to low rate of exclusive breastfeeding in Bangladesh.
\end{abstract}

Key words: Breastfeeding; Barrier; Urban mother

J Enam Med Col 2016; 6(2): 88-92

\section{Introduction}

Breastfeeding is the unique source of nutrition that plays an important role in the growth, development and survival of the infants. Infants need appropriate nutrition, protection and affection. Exclusive breastfeeding meets the needs and gives the best start. ${ }^{1}$ Exclusive breastfeeding means the infant receives no solid or liquid foods apart from breast milk, with the exception of vitamins, minerals or medicine.

It contains a balance of nutrients and other compounds that act against virus, bacteria and parasites. It works as baby's first immunization. ${ }^{2}$ Exclusive breastfeeding for six months has been found to reduce the risk of diarrhe ${ }^{3}$ and respiratory illness ${ }^{3}$ compared with exclusive breastfeeding for 3 months.

In 2003 , Lancet series on child summarized that $13 \%$ to $15 \%$ of under-five deaths in resource poor countries could be prevented through achievement of $90 \%$ coverage with exclusive breastfeeding alone. ${ }^{4}$ Exclusive breastfeeding is also linked with childhood intelligence, adult health and protective role in obesity, diabetes and hypertension. 5

1. Assistant Professor, Department of Paediatrics, Enam Medical College \& Hospital, Savar, Dhaka

2. Professor, Department of Paediatrics, Dhaka Shishu Hospital, Dhaka

3. Professor, Department of Paediatrics, Women \& Children Hospital, Dhaka

4. Classified Specialist, Department of Medicine, Combined Military Hospital, Dhaka

Correspondence Lazina Sharmin,Email: drlazina22@yahoo.com 
In Bangladesh, there is tremendous erosion in breastfeeding with rapid urbanization. Bottle feeding has taken an upper hand over infant-mother bonding and psychological communication of mother with the newborn. Erosion in breastfeeding practices results in increase in the infant mortality and morbidity due to various diseases and the import of breast milk substitute (BMS) is imposing a considerable damage on the economy of this country as well. Current data show that $38 \%$ of children aged 2-3 months are exclusively breastfed and $23 \%$ of children are given complementary feeding before 6 months. ${ }^{6}$ The rate of consumption of baby formula in infants aged 4-7 months almost doubled since 2000 and is higher in urban areas. ${ }^{7}$ Talukder et $\mathrm{al}^{8}$ showed that only $66 \%$ of urban elite exclusively breastfed their children at birth, $42 \%$ at one month and $12 \%$ at 4 months.

Maternal and social factors and factors related to infants and health care system influence duration of breastfeeding and can overshadow the unquestionable benefits of breastfeeding. The present study aimed to identify the barriers of exclusive breastfeeding up to six months.

\section{Materials and Methods}

This cross sectional study was done among 125 infant (1-12 months)-mother pairs admitted and attending OPD in Dhaka Shishu Hospital during January to June 2011. All mothers with infants $(<12$ months) who started breastfeeding after birth and continued it or mothers with partial and complete failure to breastfeed were included in the study. Mother-infant pairs were divided into two groups based on continuation of only breastfeeding up to six months. Mothers with very sick neonates and of adopted infants were excluded.

Mothers who continued breastfeeding up to six months were included in exclusive breastfeeding (EBF) group and mothers with partial and complete failure to breastfeed up to six months were included in nonexclusive breastfeeding (non-EBF) group. Outcomes were compared between two groups.

The study was conducted by the researcher herself after taking consent from eligible mothers by face-to-face interview using a structured questionnaire which included mothers' background information regarding morbidity and barriers to EBF. After collection, data were documented in case record form and analysis was done by SPSS version 12.0. Independent effect on study variables on total duration of exclusive breastfeeding were estimated by using chi-square test. The statistical significance level was set at $\mathrm{p}<0.05$.

Prior to the commencement of the study the research protocol was approved by Ethical Review Committee. Written informed consent was taken from each subject after informing them the objects of study, the risk and benefits, confidential handling of person's information and voluntary nature of participation and the right of the subject to withdraw from the study.

\section{Results}

In the present study the rate of EBF was $27.2 \%$ and non-EBF was $72.8 \%$ among the 125 eligible motherinfant pairs. Among 125 mothers $32.8 \%$ exclusively breastfed up to $1-2$ months, $40 \%$ up to 4 months and $27.2 \%$ up to 5-6 months (Fig 1). The average age of the infants was $8.4 \pm 2$ months and $7.14 \pm 3$ months in EBF and non-EBF groups respectively. Among the study subjects $91 \%$ mothers in EBF group and $87.9 \%$ mothers in non-EBF group were housewives. There was significant difference $(\mathrm{p}<0.05)$ between these two groups.

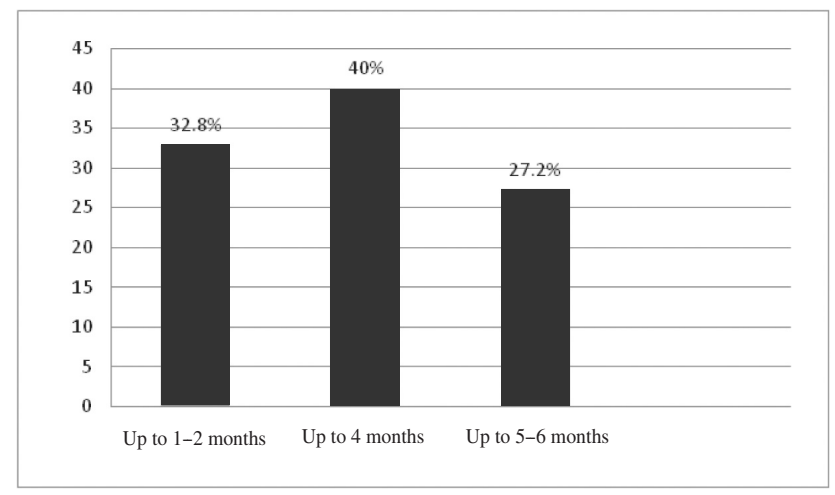

Fig 1. Duration of exclusive breastfeeding among infants $(n=125)$

Table I shows the rate of EBF based on parity and delivery type. Eighty three mothers delivered their babies per vaginally and 41 by LUCS. Ninety mothers were primiparous and 35 were multiparous.

Table II shows some mother factors associated with EBF. It shows that knowledge of mother about importance of breastfeeding and knowledge about proper positioning and attachment was $98.5 \%$ and $100 \%$ respectively in EBF group. But in non-breastfed group it was $98.9 \%$ and $92.3 \%$ respectively. There was also statistically significant difference between EBF and 
non-EBF groups regarding mother's thought that they did not have enough milk.

Table III shows social factors like influence of husband and other members of the family. In EBF group it was $2.9 \%$ and in non-EBF group 22\%. About $64.8 \%$ mothers were found to have advised by doctors to give supplementation in non-EBF group compared to none in EBF group.

Table I: Rate of EBF based on parity and delivery type

\begin{tabular}{|c|c|c|c|}
\hline Variables & EBF & Non-EBF & p values \\
\hline Parity & & & \\
\hline Primi (n=90) & $21(23.3 \%)$ & $69(76.7)$ & 0.125 \\
\hline Multi $(\mathrm{n}=35)$ & $13(37.1 \%)$ & $22(62.9 \%)$ & \\
\hline Delivery type & & & \\
\hline NVD (n=83) & $20(24.1 \%)$ & $63(75.9 \%)$ & 0.293 \\
\hline LUCS (n=41) & $14(34.1 \%)$ & $27(65.9 \%)$ & \\
\hline
\end{tabular}

$\mathrm{p}$ value was reached by Chi-square test

Table II: Barriers to EBF in relation to mother factors

\begin{tabular}{|c|c|c|c|}
\hline Characteristics & $\begin{array}{l}\text { EBF group } \\
(n=34)\end{array}$ & $\begin{array}{l}\text { Non-EBF group } \\
\qquad(\mathrm{n}=91)\end{array}$ & $\mathrm{p}$ value \\
\hline \multicolumn{4}{|l|}{$\begin{array}{l}\text { Knowledge about } \\
\text { duration of EBF }\end{array}$} \\
\hline Yes & $33(98.5 \%)$ & $75(82.4 \%)$ & \multirow{2}{*}{$<0.001$} \\
\hline No & $1(1.5 \%)$ & $16(17.6 \%)$ & \\
\hline \multicolumn{4}{|l|}{$\begin{array}{l}\text { Knowledge about } \\
\text { importance of } \\
\text { breastfeeding }\end{array}$} \\
\hline Yes & $33(98.5 \%$ & $90(98.9 \%)$ & \multirow{2}{*}{0.302} \\
\hline No & $1(1.5 \%)$ & $1(1.1 \%)$ & \\
\hline \multicolumn{4}{|c|}{$\begin{array}{l}\text { Using faulty technique } \\
\text { (poor position and } \\
\text { attachment) }\end{array}$} \\
\hline Yes & $0(0 \%)$ & $7(7.7 \%)$ & \multirow{2}{*}{$<0.001$} \\
\hline No & $34(100 \%)$ & $84(92.3 \%)$ & \\
\hline \multicolumn{4}{|l|}{$\begin{array}{l}\text { Dissatisfaction } \\
\text { regarding baby's } \\
\text { growth }\end{array}$} \\
\hline Yes & $1(2.9 \%)$ & $45(49.5 \%)$ & \multirow{2}{*}{0.000} \\
\hline No & $33(97.1 \%)$ & $46(50.5 \%)$ & \\
\hline
\end{tabular}

$\mathrm{p}$ value was reached by Chi-square test
Table III: Barriers to EBF in relation to social factors

\begin{tabular}{|c|c|c|c|}
\hline Characteristics & $\begin{array}{l}\text { EBF group } \\
\quad(n=34)\end{array}$ & $\begin{array}{l}\text { Non-EBF group } \\
\quad(n=91)\end{array}$ & $\mathrm{p}$ values \\
\hline \multicolumn{4}{|l|}{$\begin{array}{l}\text { Influence of } \\
\text { husband and } \\
\text { others }\end{array}$} \\
\hline Yes & $1(2.9 \%)$ & $20(22 \%)$ & \multirow{2}{*}{$<0.001$} \\
\hline No & $33(97.1 \%)$ & $71(78 \%)$ & \\
\hline \multicolumn{4}{|l|}{$\begin{array}{l}\text { Advised by } \\
\text { doctors }\end{array}$} \\
\hline Yes & $0(0 \%)$ & $59(64.8 \%)$ & \multirow{2}{*}{$<0.001$} \\
\hline No & $34(100 \%)$ & $32(35.2 \%)$ & \\
\hline \multicolumn{4}{|l|}{$\begin{array}{l}\text { Influence of } \\
\text { commercial } \\
\text { advertisement }\end{array}$} \\
\hline Yes & $0(0 \%)$ & $26(26.6 \%)$ & \multirow{2}{*}{$<0.001$} \\
\hline No & $34(100 \%)$ & $65(73.4 \%)$ & \\
\hline \multicolumn{4}{|l|}{$\begin{array}{l}\text { Joining in } \\
\text { work place }\end{array}$} \\
\hline Yes & $0(0 \%)$ & $9(9.9 \%)$ & \multirow{2}{*}{0.007} \\
\hline No & $34(100 \%)$ & $82(90.1 \%)$ & \\
\hline
\end{tabular}

$\mathrm{p}$ value was reached by Chi-square test

In our study it was found that in EBF group 2.9\% and in non-EBF group $49.5 \%$ mothers discontinued early breastfeeding as they were not satisfied with baby growth. It was also found that $90.1 \%$ mothers could not continue exclusive breast feeding due to joining in work.

\section{Discussion}

In the present study, duration of exclusive breastfeeding up to 2 months was $32.8 \%$, up to 3-4 months was $40 \%$ and up to 5-6 months was only $27.2 \%$. In spite of universal breastfeeding practice in Bangladesh, exclusive breastfeeding rate is low. In a survey the prevalence of exclusive breastfeeding till 6 months was only $43 \%$. $^{9}$ The rate of exclusive breastfeeding in the present study was less than it was found in national survey. Another study also showed that only $23 \%$ of urban mothers breastfed their children up to 4 months and it declined to $16 \%$ at 6 months. ${ }^{10}$ Talukder et al ${ }^{11}$ also showed that only $66 \%$ of the urban elite exclusively breastfed their children at birth, $42 \%$ at one month and $12 \%$ at fourth month. 
This study found that exclusive breastfeeding was more common among multiparous mothers. The studies conducted in Malaysia and Hongkong reported similar findings where mothers with their first child having less knowledge and skill in breastfeeding as they had less confidence to breastfeed their infants. ${ }^{12}$

Exclusive breastfeeding was more common among mothers with supportive husband $(97.1 \%)$ compared to non-supportive husband. In Asian setting the husband plays a major role in decision making about family and household matters. In a study by Haider et $\mathrm{al}^{13}$ it was found that father's absence or not providing support was an important cause of breastfeeding failure. In the present study influence of other family members was also found to be negatively associated with exclusive breastfeeding.

Majority of mothers (87.8\%) started breast milk supplement because of insufficient breast milk production as they claimed. This psychosocial problem still remains the top most cause of breastmilk supplements. ${ }^{14}$

Mother's perception of insufficient breast milk was also common in other countries. Inch \& Garforth ${ }^{15}$ argue that the most effective ways of overcoming these problems are unrestricted breastfeeding, good positioning and appropriate and practical support.

In the present study about $49.5 \%$ mothers discontinued early breastfeeding as they were not satisfied with baby growth. Another study also showed that some mothers felt only breast milk could not provide adequate nutrition. ${ }^{16}$

Due to joining in workplace $90.1 \%$ mothers could not breastfeed their infants exclusively in this study. Similar finding was also found in another study. ${ }^{16}$ Early weaning in preparation to return to work, maternal fatigue and the difficulties in juggling the demand of work and breastfeeding may contribute to this issue.

A study by Rafeal et al ${ }^{17}$ showed that commercial advertisement of breastfeeding supplements had a negative association with EBF. In our study it was also found that about $26.6 \%$ mothers were influenced by commercial advertisement which was statistically significant.

In this study health care provider advised $64.8 \%$ mothers of nonexclusive breastfeeding group not to breastfeed during sickness of infants. Another study also revealed similar findings. ${ }^{1}$ But it could not be confirmed by some mothers that they were qualified doctors or quacks. Further studies should be done in this respect.

The present study identified some barriers which contribute to the low rate of exclusive breastfeeding up to 6 months. The study also identified that failure to breastfeed is more common in working mothers than in housewives. Primi mothers fail to continue exclusive breastfeeding more than multiparous mothers. Insufficient milk production as claimed by mothers was the top most barrier to exclusive breastfeeding. Other barriers were joining in workplace, advice by health care workers for supplementation and dissatisfaction about baby's growth. The social barrier includes lack of husbands' support, influences of mother-in-laws and other close relatives and sickness of mothers. Although most of the mothers knew about duration of exclusive breastfeeding and importance of it, knowledge of proper positioning and attachment was lacking in majority of them.

To promote exclusive breastfeeding and to overcome the barriers for EBF, following measures are recommended.

- Antenatal counseling for exclusive breastfeeding and demonstration of proper positioning and attachment to all mothers must be ensured during antenatal check-up.

- Antenatal counseling must include husband and if possible other family members as they can support mothers during lactation.

- After delivery help should be offered for starting breastfeeding as early as within one hour, to continue EBF up to 6 months and till 2 years.

- All health care personnel should always encourage exclusive breastfeeding and strict adherence to it.

- All health care providers caring the mothers should be properly trained.

- Appropriate campaign through media.

- Maternity leave for 6 months should be established for all lactating mothers and provision of day care practice should be done.

- Correct and specific intervention should focus on mothers who are at risk of early discontinuation of breastfeeding. 
- Future breastfeeding programme in Bangladesh should give special attention to the factors affecting duration of breastfeeding.

\section{References}

1. Infant and young children feeding. WHO, 2009.

2. Talukder MQK. How to initate breastfeeding. National conference, Bangladesh Neonatal Forum, 2011.

3. Kramer MS, Guo T, Platt RW, Sevkovskaya Z, Dzikovish $\mathrm{Z}$, Collet JP et al. Infant growth and health outcomes associated with 3 compared to 6 months exclusive breast feeding. Am J Cli Nutr 2003; 70: 376-385.

4. Jones G, Steketee RW, Black RE, Bhulta ZA, Morris SS (Bellagio Child Survival Study Group). How many child death can be prevented this year? Lancet 2003: 362: 65-67.

5. Horta BL, Bahl R, Martines JC, Victoria CG (eds). Evidence on the long term effects on breastfeeding: systemic review and meta-analysis. World Health Organization, Geneva, 2007.

6. Bangladesh - Demographic and Health Survey, Dhaka: National Institute of Population Research and Training; 2005: 165-172.

7. Ahmed FU, Rahman ME, Alam MS. Pre-lacteal feeding: influencing factors and relation to establishment of lactation. Bangladesh Med Res Counc Bull 1996; 22: 60-64.

8. Talukder MQK. Bangladesh campaigning of promotion of breastfeeding. Bangladesh Journal of Child Health 1992; 16: 25-31.

9. Bangladesh — Demographic and Health Survey 2007.
10. Senath U, Dibley MJ, Agho KE. Breastfeeding and practice and associated factors among children under 24 months of age in Timor-lestle. Eur J Clin Nutri 2000: 61(3): 387-397.

11. Talukder MQ, Feroz ASM, Huq S, Khan N. Breastfeeding trends in Dhaka urban affluent. Bangladesh Journal of Child Health 1983; 12: 4-6.

12. Leung TF, Tam WH, Hung ECW, Fok TF, Wong GWK. Socio-demographic and atopic factors affecting breastfeeding intention to Chinese mothers. J Paediatrics Child Health 2003; 39(6): 460-464.

13. Haider R, Kabir I, Hamdani JD, Habte D. Reasons for failure of breastfeeding counseling: mothers' perspective in Bangladesh. Bulletin of the World Health Organization 1997; 75(3): 191-196.

14. Minchin MK. Positioning for breastfeeding. Birth 1989; 16(2): 67-74.

15. Inch S, Garforth S. Establishing and maintaining breastfeeding, a guide to effective care in pregnancy and child birth. Oxford University Press, 1989: 1350-1374.

16. Da Vanzo J, Sine J, Peterson CE, Haggo J. Reversal of the decline in breasfeeding in peninsular Malaysia. Rand labor and population programme paper: series 93-29, 1993.

17. Haider R, Kabir I, Huntley A. Effect to community based peer counselors on exclusive breastfeeding practices in Dhaka, Bangladesh: a randomized controlled trial. Lancet 2000; 356: 1643-1647.

18. Haque M, Hussain F, Sarker M, Haque AK, Ara A, Sultana S. Breastfeeding counseling and its effect on the prevalence of exclusive breastfeeding. J Health Population and Nutrition 2002; 20: 312-316. 